\title{
PENINGKATAN HASIL BELAJAR TEKNIK DASAR BLOCK BOLAVOLI MELALUI PEMBELAJARAN BERBASIS MEDIA
}

\author{
Muhammad Ishaq Gery ${ }^{1}$, Muhammad Aspar ${ }^{2}$ \\ Universitas Muhammadiyah Jakarta \\ m.ishaqgery@umj.ac.id \\ muhammad.aspar@umj.ac.id
}

\begin{abstract}
Abstrak
Block menjadi teknik dasar permainan bolavoli yang sangat jarang diberikan dan ditingkatkan pada permainan bolavoli, terutama pada siswa. Block bolavoli merupakan upaya pemain untuk menghentikan serangan boladidepan net dan membelokkan bola kewilayah lawan. penelitian ini dilakukan pada siswa kelas XI SMA 22 Jakarta.yang berjumlah 20 orang. Pada pertemuan I dilakukan sebanyak 3 kali, dimulai dengan tes awal sebelum diberikan perlakuan dan tes akhir setelah diberikan perlakuan. Hasil siswa yang tuntas sebanyak 14 siswa dengan ketuntasan 60\%. Siklus pertama, tingkat keberhasilan ditentukan yaitu 80\%, maka dapat dinyatakan bahwa siklus I belum berhasil. Penelitian dilanjutkan pada siklus II dengan perubahan dan penambahan pada tiap tindakan pembelajaran sebelumnya. Pada siklus II akan dilakukan 3 pertemuan, hasil tes akhir menunjukkan bahwa sebanyak 18 siswa memperoleh nilai tuntas dengan presentase sebesar 90. Hasil penelitian ini dapat dinyatakan berhasil dengan berdasar pada kriteria keberhasilan $80 \%$.
\end{abstract}

\section{Kata Kunci: Bolavoli, Block, Pembelajaran}

\begin{abstract}
Abstrack
Block is a basic technique for playing volleyball which is rarely given and improved in volleyball games, especially for students. Block volleyball is an attempt by the player to stop the ball attack in front of the net and deflect the ball into the opponent's territory. This research was conducted in class XI 22 Jakarta high school students, amounting to 20 people. At the first meeting conducted 3 times, starting with the initial test before being given treatment and the final test after being given treatment. The results of students who completed as many as 14 students with $60 \%$ completeness. The first cycle, the success rate is determined at $80 \%$, it can be stated that the first cycle has not been successful. The study continued in the second cycle with changes and additions to each previous learning action. In cycle II there will be 3 meetings, the final test results show that as many as 18 students get a complete score with a percentage of 90 . The results of this study can be declared successful based on the $80 \%$ success criteria.
\end{abstract}

Key Words:VolleyBall, Block, Learning

Dipublikasikan Oleh :

UPT Publikasi dan Pengelolaan Jurnal

Universitas Islam Kalimantan Muhammad Arsyad Al-Banjari Banjarmasin 


\section{PENDAHULUAN}

Pendidik merupakan aktor yang bertugas dalam menciptakan suasana pembelajaran agar lebih menarik, kreatif, dan inovatif agar siswa dapat belajar dengan baik dan bersemangat. Suasana pembelajaran yang demikian akan dapat meningkatkan prestasi belajar anak secara optimal. Salah satu nya pada mata pelajaran pendidikan jasmani.

Pendidikan jasmani adalah suatu proses pendidikan yang bertujuan untuk meningkatkan kebugaran jasmani dan mengembangkan kemampuan gerak (motorik). Tidak hanya itu, pendidikan jasmani juga berorientasi pada aspek pengetahuan (kognitif) dan sikap (afektif). Yang artinya, Melalui suatu gerakan siswa dituntun untuk mengetahui cara melakukan gerakan tersebut, mengetahui kebermanfaatan gerakan dan juga mampu menunjukkan perilaku-perilaku positif dalam pembelajaran. Begitu pentingnya peranan pendidikan jasmani maka harus disampaikan dengan baik dan benar. Pendidikan jasmani mempunyai beragam materi didalamnya yang meliputi tentang budaya hidup sehat dan cabang-cabang olahraga. Salah satu cabang olahraga tersebut adalah Bolavoli.

Bolavoli merupakan cabang olahraga yang selalu berkembang, baik dilihat dari kualitas kompetisi yang dilakukan ataupun penguasaan teknik yang dimiliki oleh para pemain bolavoli itu sendiri. Perkembangannya merupakan wujud dari implementasi ilmu pengetahuan dan teknologi yang dewasa ini menjadi bagian yang sangat penting dalam perkembangan olahraga pada umumnya. Dimulai dari penemuan model latihan, pemanfaatan peralatan-peralatan latihan maupun berbagai penemuan lain seperti pemanfaatan laboratorium, dan lain-lain.

Dari segi perorangan, seorang pemain bolavoli harusnya memiliki dasar bermain bolavoli yang baik dan didukung oleh kemampuan fisik yang baik. The modern volleyball game is characterized byspeed and variety of actions, continuous improvement of technique, and an ever higher spiking point, creativity in attack combinations andflexibility in choosing the defence system (Reitmayer \& Grădinaru, 2014). Agar dapat melakukan gerakan teknik dasar bolavoli yang baik dan mumpuni. Bahwa syarat-syarat bibit pemain bolavoli yang baik antara lain memiliki syarat fisik, yaitu kesehatan yang baik, tidak memiliki cacat tubuh, postur tubuh tinggi, memiliki unsur kondisi fisik yang baik (kekuatan, kecepatan, kelincahan, daya tahan, koordinasi kelentukan, power) dan secara fisiologis memiliki kemampuan kerja otot yang baik.

Hasil pengamatan yang dilakukan peneliti, didukung dari informasi dari guru pendidikan jasmani, ditemukan bahwa siswa hampir semuanya tidak bisa melakukan block bolavoli serta dibuktikan dengan nilai teknik bolavoli siswa yang rendah. Maka dari itu peneliti menilaiperlu adanya cara yang tepat dalam proses pembelajaran untuk meningkatkan hasil pembelajaran, yaitu dengan pembelajaran berbasis media. Melalui pembelajaran berbasis media peneliti berharap bahwa siswa akan dengan mudah mengerti tiap gerakan yang ada dalam rangkaian gerak smash bolavoli. Siswa akan belajar bagian bagian pada rangkaian gerakan smash bolavoli secara terpisah dengan bantuan media. Media pembelajaran adalah suatu alat yang dapat membantu siswa supaya terjadi proses belajar mengajar (Nana Sudjana, 2010:153).

Media dimaksud harus menunjang tujuan proses belajar mengajar dan juga membantu proses berfikir siswa agar dapat dengan segera memahami informasi tersebut (Samsudin, 2008:53).

\section{METODE}

Penelitian ini menggunakan metodepenelitian tindakan.Penelitian tindakan merupakan salah satu varian dari penelitian terapan(applied research) dan termasuk dalam tipe penelitian evaluasi (evaluation research) yang dimaksudkan untuk mendekatkan atau menghilangkan gap antara teori (espoused theory) dengan praktik (theory in use) (Uhar Suharsaputra, 2014:247). Penelitian tindakan dapat memiliki lima kategori fungsi yaitu, 1) Sebagai alat untuk mengatasi masalah - masalah yang didiagnosis dalam situasi spesifik, atau untuk meningkatkan keadaan tertentu dengan cara tertentu, 2) Sebagai alat pelatihan dalam jabatan, membekali guru dengan keterampilan dan metode baru dan mendorong timbulnya kesadaran diri, 3) Sebagai alat untuk memasukkan pendekatan tambahan atau inovatif terhadap pengajaran dan pembelajaran kedalam sistem yang dalam keadaan normal menghambat inovasi dan perubahan, 4) Sebagai alat untuk meningkatkan komunikasi yang biasanya buruk antara guru dan peneliti, 5) Sebagai alat untuk menyediakan alternatif bagi pendekatan yang subyektif, impresionistik terhadap pemecahan masalah kelas (Suwarsih madya, 2006:9).

Penelitian tindakan dilakukan dalam beberapa putaran (siklus). Jumlah putaran tidak di tentukan karena indikator keberhasilan di ukur dari kepuasan penelitian terhadap pencapaian hasil. Untuk model penelitian tindakan yang peneliti gunakan pada penelitian ini adalah model Kemmis dan Taggart. Penelitian tindakan Pada kemmis dan taggart menggunakan siklus yang mana dalam satu siklus terdapat empat tahap yang harus dilalui diantaranya perencanaan, tindakan, observasi dan refleksi. Berikut disain peneilitian tindakan menurut Kemmis dan Taggart:

Dipublikasikan Oleh : 


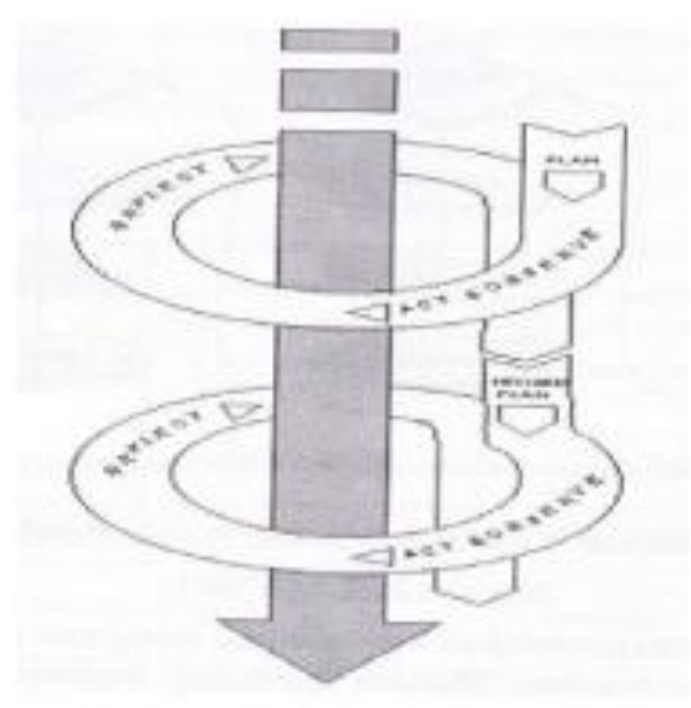

Gambar 1. Desain Model Kemmis Taggart

Desain penelitian yang digunakan adalah model Kemmis dan Mc. Taggart, yang berupa satu siklus atau kegiatan yang meliputi tahap-tahap rancangan pada setiap putarannya yaitu: (1) Perencanaan/ Planning, (2) Tindakan/ Acting, (3) Pengamatan/ Observing, (4) Refleksi/ reflecting, dan akan diadakan revisi perencanaan pada siklus ulang jika masih diperlukan.

\section{HASIL DAN PEMBAHASAN}

Hasil pengambilan data pada pra siklus dapat diketahui sebanyak 8 siswa yang mendapat nilai di bawah 60, 6 siswa yang memperoleh nilai cukup (60-74), 6 siswa yang memperoleh nilai baik (75-89) dan belum ada siswa yang mampu medapat nilai diatas 90, sehingga dapat di Tarik kesimpulan bahwa sebanyak 14 siswa $(60,00 \%)$ siswa belum mampu mencapai batas ketuntasan minimal yaitu: 80,00 . Sedangkan siswa yang sudah mencapai batas ketuntasan minimal adalah 6 siswa $(30,00 \%)$.

Setelah diberikan perlakuan pembelajaran block bolavoli siswa SMA 22 Jakarta secara umum dapat dikatakan baik, karena nilai ketuntasan hasil pembelajaran block bolavoli pada siklus I adalah $70 \%$ dan siswa yang belum tuntas hasil pembelajaran berjumlah 6 siswa karena belum memenuhi nilai Kriteria ketuntasan Minimal 75\%.

Sedangkan pada siklus II jumlah persentase ketuntasan hasil belajar block bolavoli mengalami peningkatan yang signifikan yaitu adalah $90,00 \%$ dan siswa yang belum tuntas hanya 2 siswa saja. Jadi antara siklus I dan siklus II terjadi peningkatan sebesar 20,00\% setelah diberi perlakuan berupa penerapan modifikasi permainan smash bulutangkis selama 2 siklus atau 6 kali pertemuan. Untuk lebih jelasnya dapat dilihat dari diagram grafik di bawah ini.

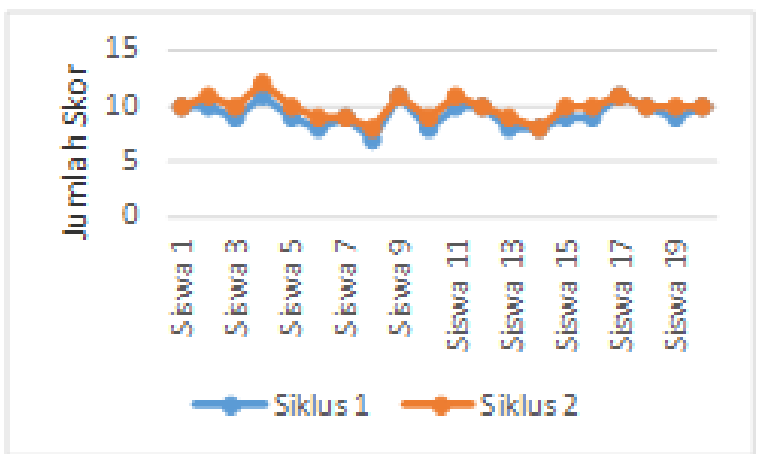

Gambar 2. Grafik Perbandingan Penilai block bolavoli Siklus I \& Siklus II

\section{PENUTUP}

Dari hasil tes pada siklus akhir merupakan paparan data hasil tes block bolavoli yang di lakukan oleh peneliti dan kolaborator. Hasil penerapan media pembelajaran dapat di katakan bahwa dapat meningkatkan pembelajaran block bolavoli pada siswa SMA 22 Jakarta. Berdasarkan hasil tes penelitian di atas, maka dapat di Dipublikasikan Oleh : 
tarik kesimpulan bahwa masih ada siswa yang belum mencapai batas kriteria ketuntasan minimal 75,00 yaitu sebanyak 2 siswa dengan presentase $(10,00 \%)$ siswa. Sedangkan siswa yang sudah mencapai batas kriteria ketuntasan sejumlah 18 siswa yaitu sebesar $(90,00 \%)$.

\section{REFERENSI}

Kemmis, S \& Mc Taggart, R. 1992. The Action Research Planner. Australia: Deakin University Press.

Reitmayer, H.-E., \& Grădinaru, S. (2014). Mass And Body Composition Particularities Of Rugby Compartments. Timisoara Physical Education \& Rehabilitation Journal, 7(13), 52-57. Https://Doi.Org/10.1515/Tperj

Samsudin.(2008). PembelajaranPendidikan Jasmani Olahraga dan Kesehatan. Jakarta: Litera dan Prenada Media Group.

Sudjana, Nana. (2010). Penilaian Hasil Proses Belajar Mengajar. Bandung: PT Remaja Rosdakarya.

Suharsaputra, Uhar. (2014). Metode Penelitian Kuantitatif, Kualitatif, dan tindakan. Bandung: PT Refika Aditama.

Dipublikasikan Oleh : 